Scientific Visualization, 2019, volume 11, number 2, pages 73 - 87, DOI: 10.26583/sv.11.2.06

\title{
Plinius: A Visualization System of Costa Rica's Tectonic Plates
}

\author{
F. Hernández-Castro 1,A,B, J. Monge-Fallas 2,A \\ A Instituto Tecnológico de Costa Rica, Costa Rica \\ B Hochschule für Gestaltung Schwäbisch Gmünd, Germany \\ ${ }^{1}$ ORCID: oooo-0003-3589-4588, franhernandez@itcr.ac.cr \\ 2 ORCID: 0000-0002-1651-3543, jomonge@itcr.ac.cr
}

\begin{abstract}
The Volcanological and Seismological Observatory of Costa Rica (OVSICORI) has been recording and archiving seismic activity data in Costa Rica since 1984.

We have designed and implemented a visualization tool, Plinius, to analyze the $3 \mathrm{D}$ location of 119206 archived earthquakes occurring from 1984-2016, providing views from every desired angle and other specific needs of this scientific domain.

Using Plinius, OVSICORI seismologists can visualize the convergence of different tectonic plates in Costa Rica, detect new seismic activity, and facilitate necessary data management regarding the country's geography. Most of the existing tools for this kind of task are $2 \mathrm{D}$ and do not have essential data filters for the domain; by contrast, Plinius enables scientists to analyze all the data in a $3 \mathrm{D}$ environment and to filter it in many different ways to derive better conclusions. This article describes Plinius and its potential.
\end{abstract}

Keywords: Seismic interpretation, earthquakes, hypocenter visualization, data visualization, interactive visualization, data interpretation, visualization paradigms.

\section{Introduction}

Despite Costa Rica's small size (a mere $51000 \mathrm{~km}^{2}$ ), it is the site of four converging tectonic plates - the Cocos, Caribbean, Nazca, and South American plates - as well as a small block, referred to as the Panama Block. OVSICORI comprises approximately 85 geodynamic GPS stations deployed throughout the country. These stations, responsible for recording Costa $\mathrm{Ri}-$ ca's seismic activity, registered a mean of 3725 earthquakes per year (see figure 1).

A

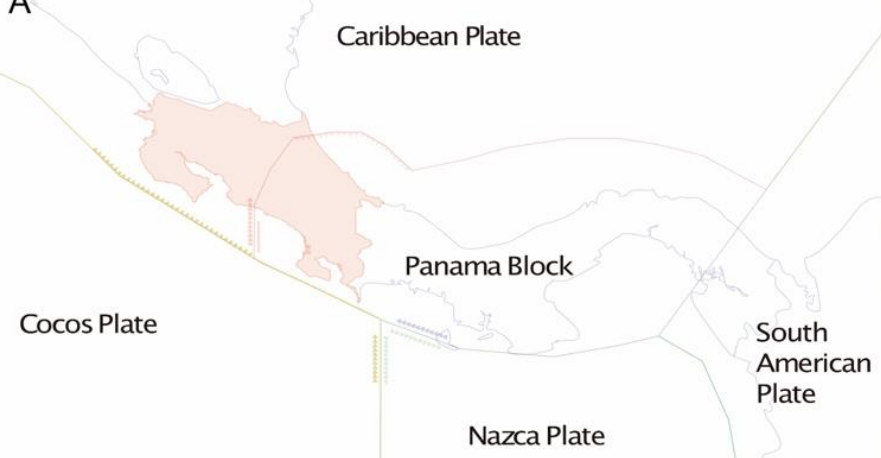

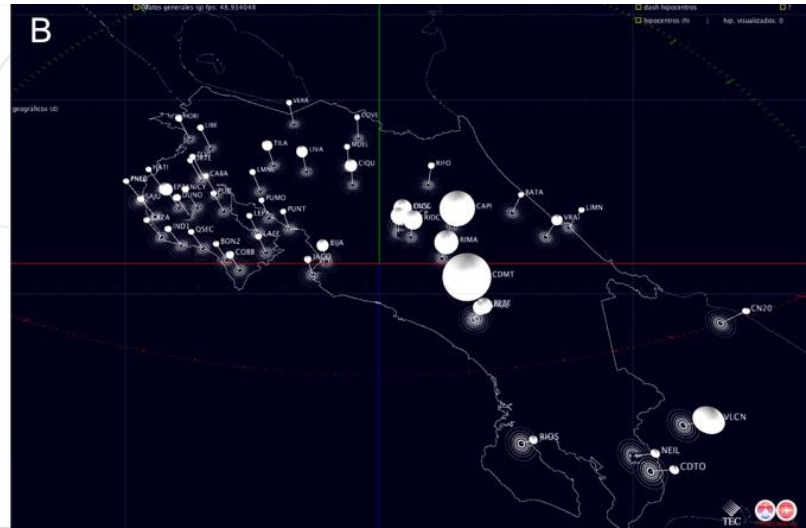

Fig. 1. (a) Tectonic plates convergence in Costa Rican territory. (b) Visualization of OVSICORI monitoring stations visualized by the Costa Rican Institute of Technology

Earthquakes are conventionally documented with two types of points, the hypocenters, which are the point at which the shock is generated, with longitude, latitude and depth and the epi- 
centers, which are the projection of the hypocenters into the surface of the earth. Plinius visualizes the earthquake hypocenters that occurred in Costa Rica in 32 years $(1984-2016)$.

We agree with $\mathrm{Li}$, Y. et al. [1] in that the task of analysis should be based on continuous process feedback from domain experts. According to seismologists, earthquakes can result from three causes: (1) local faults, (2) volcanic activity, and (3) tectonic plate subduction. Earthquakes are additionally classified by their magnitude on the Richter scale.

Earthquakes caused by local faults or volcanic activity are generally superficial while events caused by tectonic faults have typically deeper origins. We have defined a point sets $(x, y)$ such that $z=p(x, y)$ where $x, y$ is the earthquakes' epicenter and $z$ its depth. In other words, $Q(x, y, z)$ is the earthquakes' hypocenter.

With the collaboration of seismologists, we also define that if $0 \leq p(x, y) \leq 35$ the earthquakes are associated with local faults or volcanic activity, and if $35<p(x, y) \leq 200$ these are produced by tectonic plates subduction.

Another point set is defined by $(x, y)$ such that $z=m(x, y)$ where $x, y$ is the earthquakes' epicenter and $z$ its magnitude on the Richter scale. For this set, we established three intensity categories:

- $0<m(x, y) \leq 3$ low intensity;

- $3<m(x, y) \leq 6$ medium intensity;

- $6<m(x, y) \leq 8$ hight intensity, Costa Rica does not have the capacity for generating earthquakes with magnitude upper 8.

Based on this classification, we made a study of the data. Some of the more general results are presented in figure 2.

According to graphic 1 and 2 (figure 2), the most of earthquakes are produced by local faults and with low intensity. In this period the earthquakes distribution by year is very irregular, highlighting 1993 like a year with more earthquakes (8 489) and 2003 with less number of earthquakes (784).
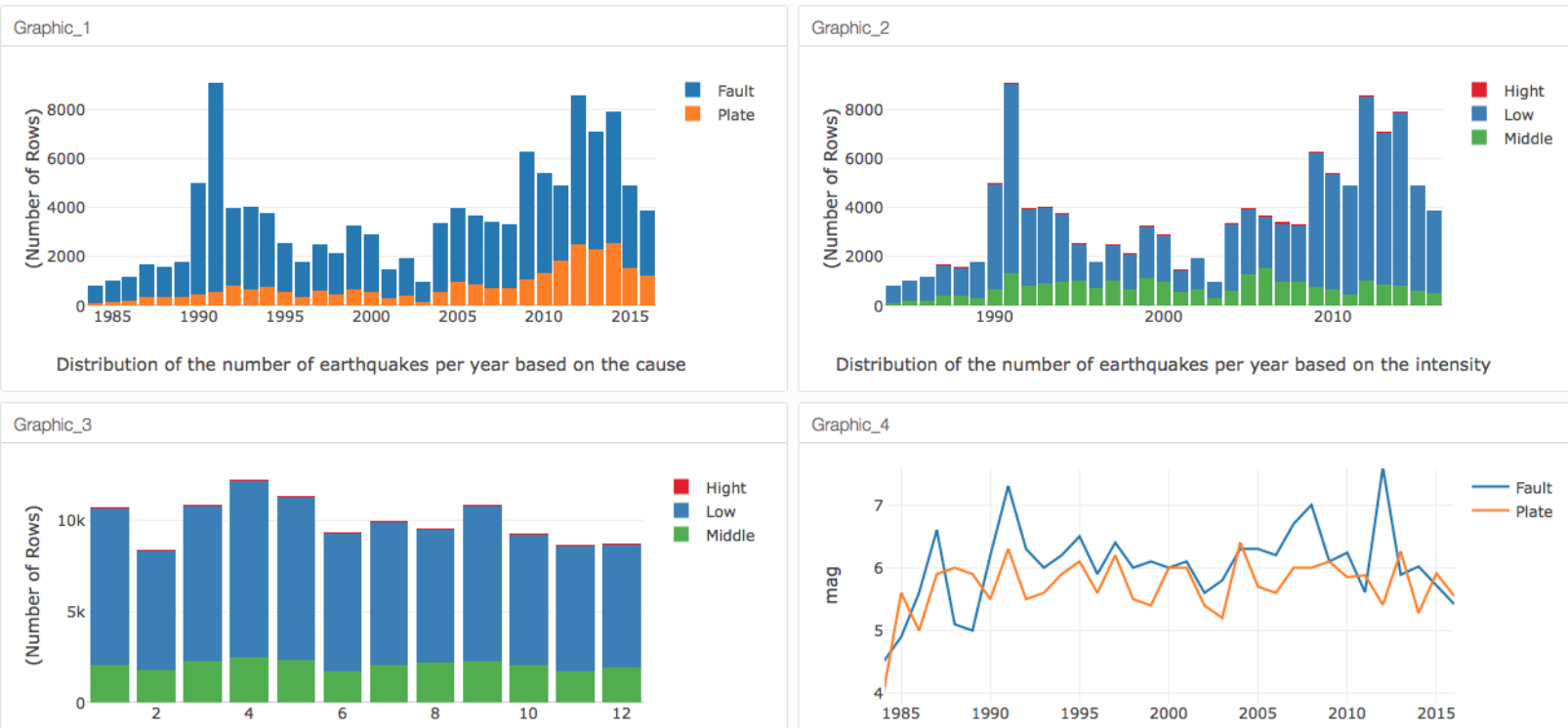
Graphic_4

Distribution of the number of earthquakes per mounths

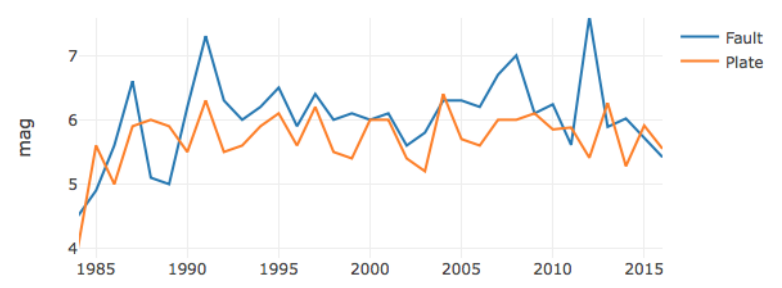

Distribution of the greatest earthquakes per year

Fig. 2. Graphic 1: Distribution of the number of earthquakes per year based on the cause. Graphic 2: Distribution of the number of earthquakes per year based on the intensity. Graphic 3: Distribution of the number of earthquakes per months. Graphic 4: Distribution of the most significant earthquakes per year

From graphic 3, we can deduce that no month has significantly higher seismic activity than the others. The last graphic (4) shows that earthquakes with greater magnitude occurred each year are produced due to local faults and clearly indicates the earthquake that occurred on 
September 5, 2012, one of the most documented earthquakes in history, about which we made a visualization [2].

The sorts of everyday questions seismologists must answer include: what kind of earthquakes are they, according to their depth? How many earthquakes are produced by local faults? How many earthquakes are generated by tectonic plate subduction? Where are there new seismic swarms? How should seismic profiles be defined to determine high-risk areas? What is the behavior of the tectonic plate and how is its geometry?

In order to answer these questions, most of the data analysis today is carried out using twodimensional systems involving latitude and longitude and using different visual strategies to render depth and magnitude, as shown in figure 3 and 4.

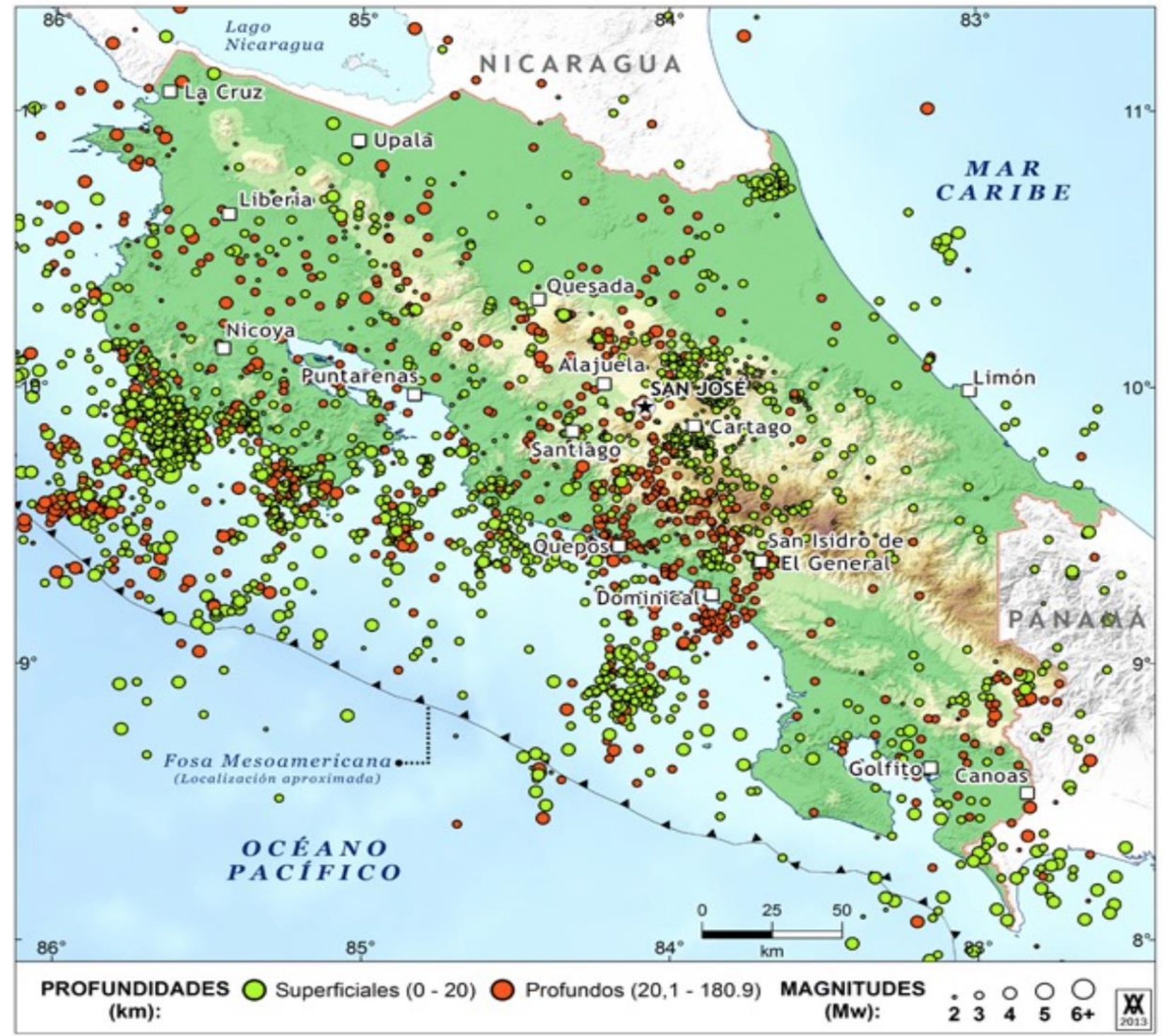

Fig. 3. Visualization of the magnitudes and depths of the earthquakes that occurred during the year 2012 (OVSICORI)

Attributes like magnitude and depth are depicted in 2D through color, size, and shape (see figure 3). For example, Kyriakopoulos et al. and Meyer and Wischgoll [3] [4] use size and color to represent the intensity of earthquakes. Dzwinel et al. [5] show the magnitude of the earthquakes and their depth by different circle radiuses and colors; the same scheme is used by Fairchild et al., but in 3D [6].

The cognitive burden of the aforementioned image is extremely high and becomes even more complex when monitoring longer time periods. 
With this type of analysis, answering questions such as which earthquakes are local or which are of tectonic origin, which in turn depends on their depth, requires a detailed observation of the symbols with which these variables are represented.

In addition, scientists use seismic profiles, such as those shown in figure 4, to work with these questions, which itself involves analyzing cross-section cuts based on depth.

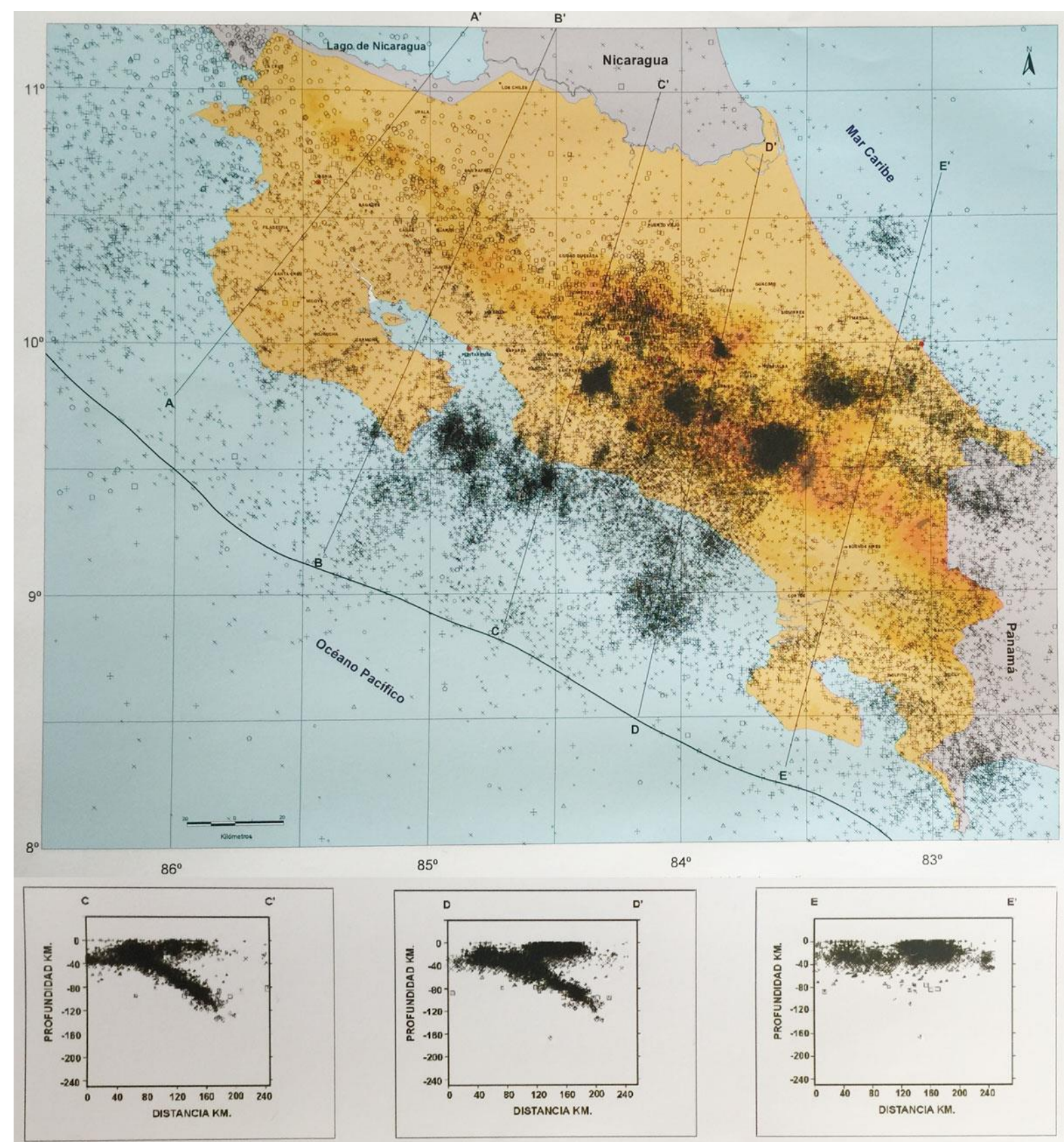

Fig. 4. Seismicity and seismic profiles in Costa Rica (OVSICORI)

The objective of profiling is to understand plate movement in the Earth's interior and its geometry. With these cross sections, the seismologists isolate each part of the subduing zone to get an idea of the geometry of the plate that is introduced underneath the other, more superficial plate. This kind of analysis is very complicated and requires a much higher capacity for abstraction that would be necessary if the representation were in three dimensions and observable at any desired angle.

Plinius (named after the famous scientist of the Roman Empire, Gaius Plinius Secundus who died after Mount Vesuvius erupted in $79 \mathrm{AD}$ ) provides seismologists with a $3 \mathrm{D}$ tool to visually analyze earthquake hypocenters, giving several filters for the data analysis and different options to save the dataset examined. 


\section{Related Works}

First of all, Plinius was built on the needs of the scientists of the domain (seismologists, volcanologists, and geologists). Therefore, its design and development incorporated some elements of both the theory of perception [7] and cognitive theory [8]. Elements of interaction taxonomy [9] - filtering, selecting, abstract/elaborate, overview/explore, and connect/relate - were integrated as well.

As Plinius was developed in a $3 \mathrm{D}$ environment, we used the basic techniques proposed by Fernandez and Fetais [10] to enhance the visual analysis.

Many systems include features for depicting attributes such as intensity and depth. For example, EQviz [11], a visualization tool for monitoring world earthquakes that only works in $2 \mathrm{D}$, uses colors ranging from yellow to red to represent earthquake magnitude, yellow being the lowest and red the highest.

SeismoGIS [12] is a toolset that supports the analysis and visualization of earthquakes measured by a seismometer station network. However, its primary task is to locate and name the events. It is a tool specifically for managing and monitoring the seismic events and is not considered to meet any of scientists' other essential requirements.

Wolfe et al. [13] present a visualization system that examines seismic data using a volumetric scheme; the resulting 3D images reveal the structure of the geological layers. Meanwhile, Patel et al. [14] have developed a 2D toolset to analyze volumetric reflection data.

None of these visualization systems can customize the analysis. That is to say, these systems do not have filters that can customize the hypocenters that are being seen, either in depth, magnitude or date. Much less is it possible with these tools to generate groups of data either associated with defined points such as volcanoes or local faults, or groups of the data related with profiles proposed at any angle, all of which are essential tasks in the work of seismologists.

A system with interesting interactivity is presented by Leonard et al. [15], who integrate some seismological characteristics in a GIS system which allows multiple views of the relevant information - albeit, being in $2 \mathrm{D}$, with a significant cognitive burden. On the other hand, the simulation of the 1906 San Francisco earthquake by Chourasia et al. [16] uses a coloring scheme to reflect the intensity of shaking. Providing visual clues to the audience about the duration of shaking and a major realism to the ground motions, this is an engaging new approach to showing another kind of qualitative data.

Other works $[17,18,19,20,21,22]$ are related to systems that analyze seismic phenomena. Nevertheless, their focus is the simulation, and most of them utilize volume-rendering methods to visualize what kind of movement occurs.

For example, in the case of the work of Yuen et al. [23], they developed a web service, WEBIS, for remote visualization of clustered seismic data within a GRID framework. Meyer \& Wischgoll [4] provide a simulation of the ground motion, both taking into account the location of epicenter magnitudes and including, interestingly, fault lines. Their simulation was performed through of finite element method (FEM) based on time-varying tetrahedral meshes.

More similar to Plinius in intent are EQviz [11], TerraVis [24], and a system developed by NEIC [25], all of which visualize the hypocenters beneath the Earth's surface. However, these systems do not facilitate the resolution of many of the necessary tasks proposed and needed by seismologists. In other words, these tools lack interactivity and therefore it is not possible for scientists to use them to analyze specific situations that are used in their daily work.

For these reasons, compared with all the previous literature our work differs in several respects. Plinius takes historical data and represents them in a $3 \mathrm{D}$ environment beneath the Earth's surface - in this case, beneath Costa Rica - allowing users to analyze the tectonic dynamics of the country. It permits filtering for different variables - such as date, magnitude, and depth - in any combination. Also, it allows users to control two kinds of seismic profiles. With the first one, they can get the cross section to visualize the plates' tectonic 
structure. With the second one, they can analyze seismic events around a particular point, such as a volcano. Most of the analysis can be saved into a file with a specific set of data or specific images of any cross-section or view.

\section{Visualization Design}

It is commonly recognized that $3 \mathrm{D}$ data should be displayed in $3 \mathrm{D}$ visualizations and $2 \mathrm{D}$ data in $2 \mathrm{D}$ visualizations. This well-known affirmation is almost always right, but never righter than in the case of this kind of data, because most research on hypocenters attempts to show $3 \mathrm{D}$ information in $2 \mathrm{D}$ contexts.

Hypocenters' distributions are generated by three factors: (1) the $3 \mathrm{D}$ geometry of tectonic plates, (2) local faults, and (3) volcanic behaviors.

Because of this, our major design goal was to provide a $3 \mathrm{D}$ visualization with a navigation system adapted to the needs of scientists, and with unique tools specially designed for these needs. This general visual paradigm was chosen based on a "target question methodology" [14], which focuses on responding to the need (or question) to be resolved by the visualization.

For 3D navigation, we use our customized approach to the conventional Virtual Trackball, Virtual Sphere or Sphere View [26].

The interface includes various dashboards: a hypocenter dashboard, geographic dashboard, and a general data dashboard. Most of these elements follow the trend called "embedded interaction", as defined by Saket et al. [27].

The hypocenter dashboard is Plinius' central dashboard and allows the user to filter data according to depth, time and magnitude. Users can visualize all of the hypocenters codified chromatically based on the magnitude, and it allows users to establish seismic profiles based on their criteria.

The geographic dashboard provides a visualization of different resolutions of the country's geographic. The "general data dashboard" presents information as a current number of frames per second and allows users to visualize the location of GPS stations and other places of reference (see figure 5).

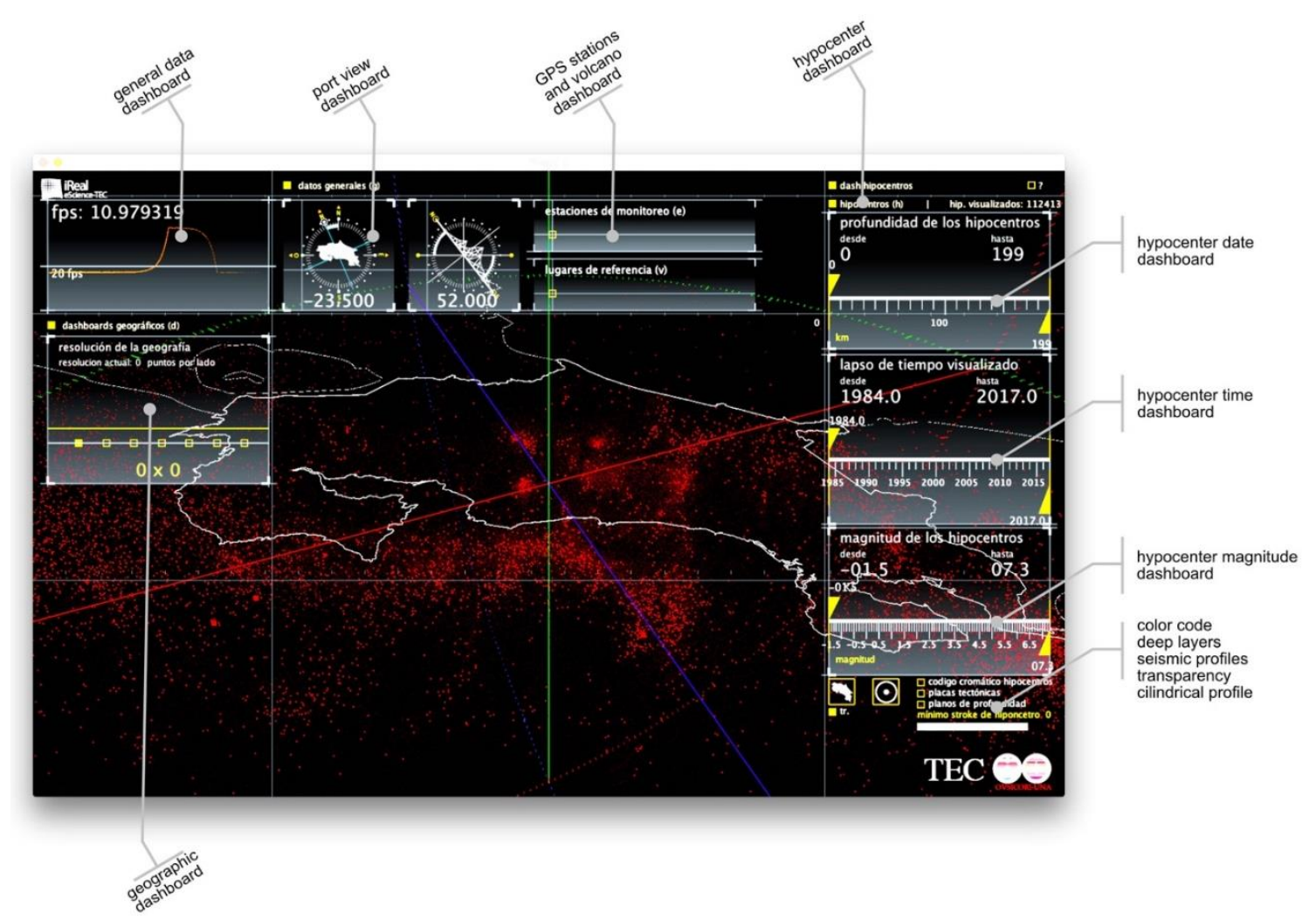

Fig. 5. Plinius Dashboards 


\subsection{User Case Scenarios}

Various work sessions were held with OVSICORI seismologists to assess Plinius and define the principal tasks required by the tool.

As stated, seismologists often work with questions such as: How many earthquakes are produced by faults? How many earthquakes are generated by tectonic plate subduction? Where are these new seismic swarms? How should seismic profiles be defined to determine high-risk areas? What is the behavior of the tectonic plate and its geometric direction?

\subsubsection{Visualization of Deeps of Hypocenters}

In order to answer questions like "How many earthquakes are produced by faults?" or "How many earthquakes are generated by tectonic plate subduction?" earthquakes are classified according to depth. For instance, earthquakes with a depth between 35 and $200 \mathrm{~km}$ frequently result from tectonic plate interaction. Earthquakes with a depth of less than $35 \mathrm{~km}$ are, most of the time, caused by local faults and volcanic behaviors. Because of this, a good visualization of deeper earthquakes would entail a good image of plate surfaces sliding against each other. However, traditionally, graphic strategies such as crosses and squares are used on the map to define depths and magnitude (as shown in figure 3 and 4).

Plinius's hypocenter dashboard allows the user to filter data according to depth, period, and magnitude. Users can visualize (in $3 \mathrm{D}$, allowing for different points of view and zoom possibilities) all of the hypocenters at each range of depth, codified chromatically based on the magnitude and period, using three double sliders to specify desired ranges.

So, if the user wishes to visualize an earthquake arising from local faults or tectonic plates, the depth filter can be used for this purpose. That's especially useful to work with questions like: "Where are there new seismic swarms?", "How should seismic profiles be defined to determine high-risk areas?"

Furthermore, there is a slider to control the opacity of points, which is very useful because surface earthquakes are significantly more frequent (80\%) than deep earthquakes and therefore changing the opacity of a case to case allows work with occlusion between data (see figure 6 and 7 ).

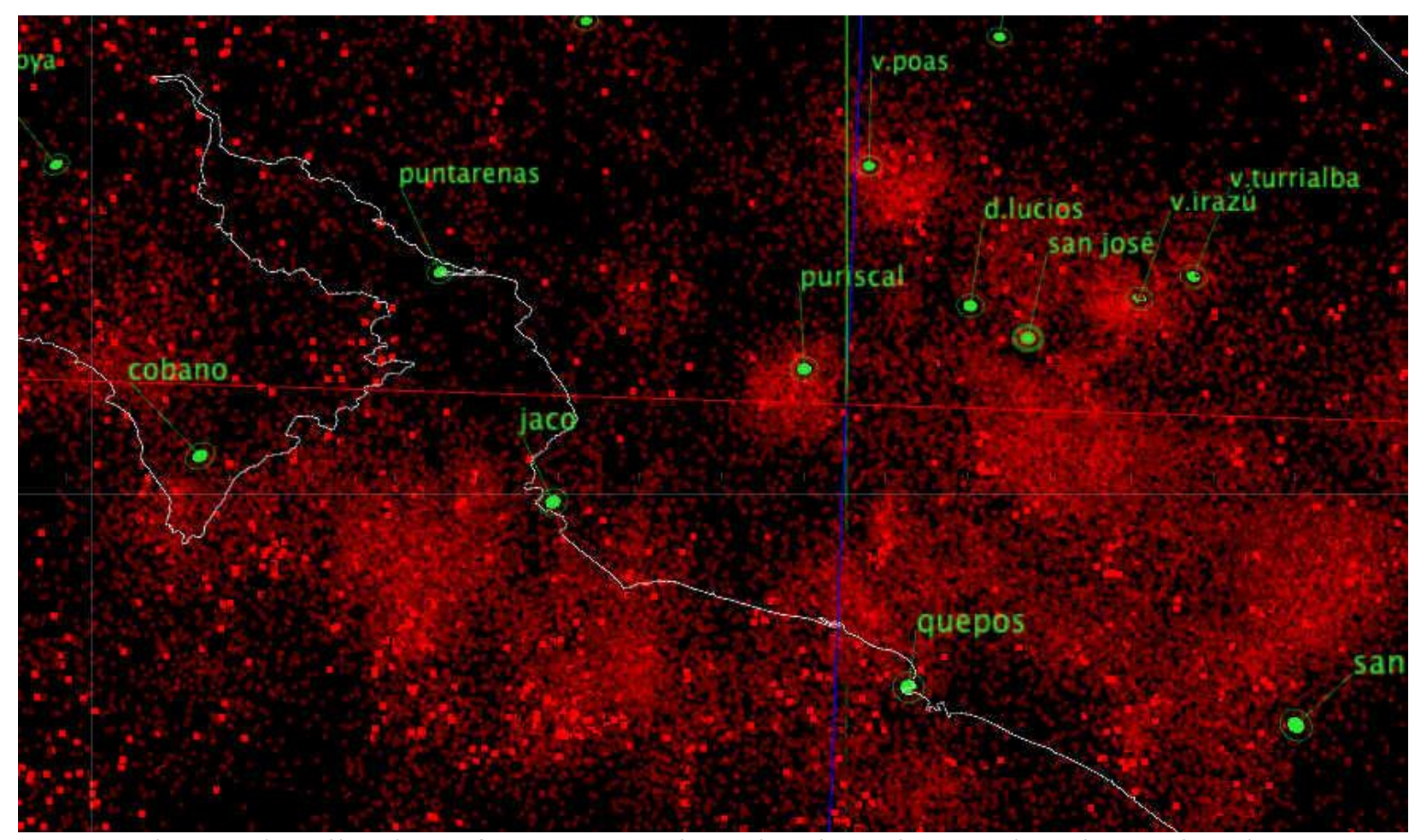

Fig. 6. Visualization of 87176 earthquakes less than $35 \mathrm{~km}$ deep, showing local fault areas 


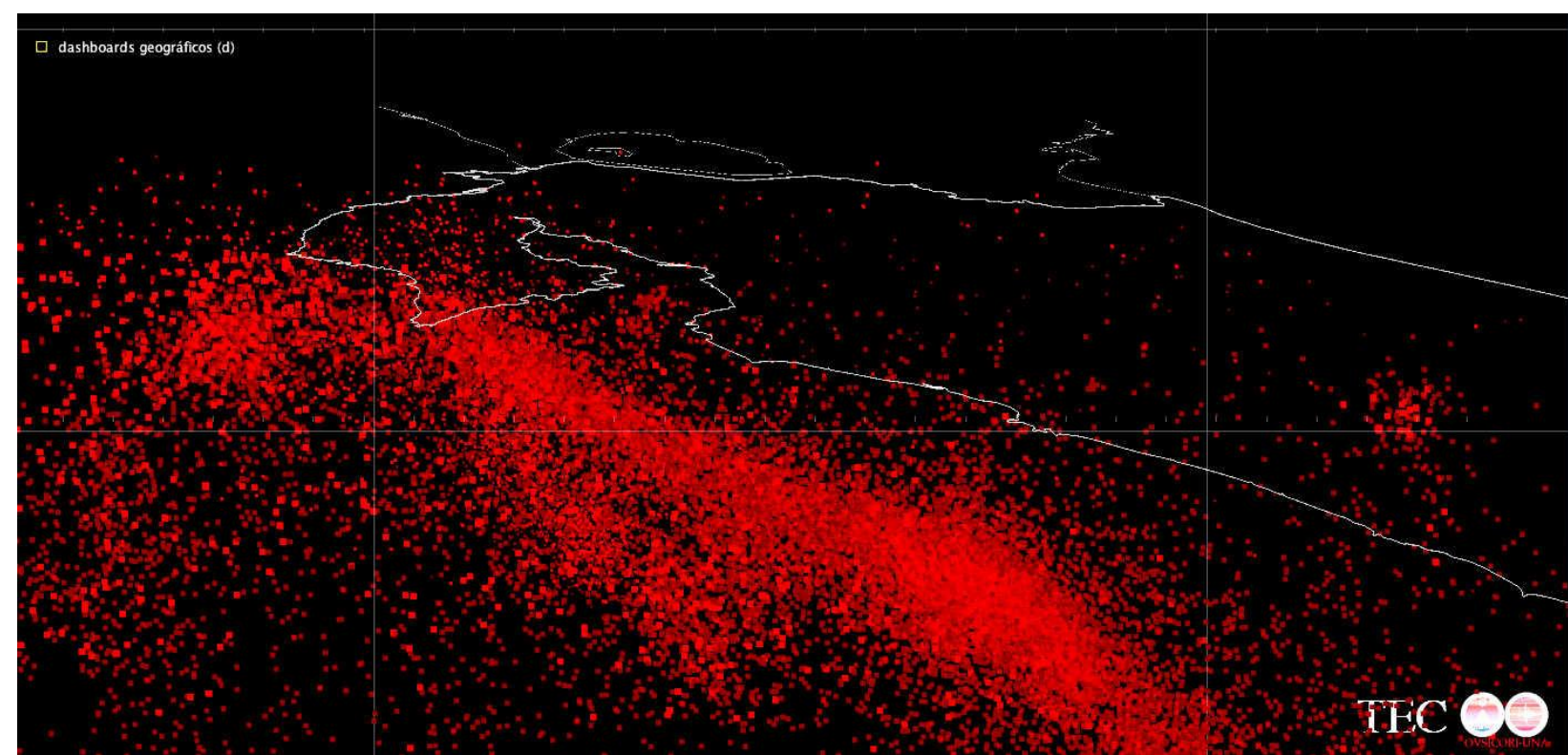

Fig. 7. Visualization of 25237 earthquakes more than $35 \mathrm{~km}$ deep, showing tectonic fault areas

\subsubsection{Earthquake Visualization Based on Magnitude}

Magnitude is another important parameter for classifying earthquakes. Seismologists must be able to visualize those areas of the country where high magnitude earthquakes have occurred and contrast them with research data. In order to visualize earthquakes according to their magnitude on Plinius, the third section of the dashboard shows a double slider that can be used to adjust the range of magnitude.

Magnitude can also be visualized in different colors using a chromatic code (figure 8). Green represents lower magnitude earthquakes and red higher magnitude earthquakes. In addition, earthquakes with more significant magnitudes (less than 20\% of the total) are represented larger than all of those with small magnitudes; this feature, together with the "opacity slider", allows scientists to fine-tune what they see.

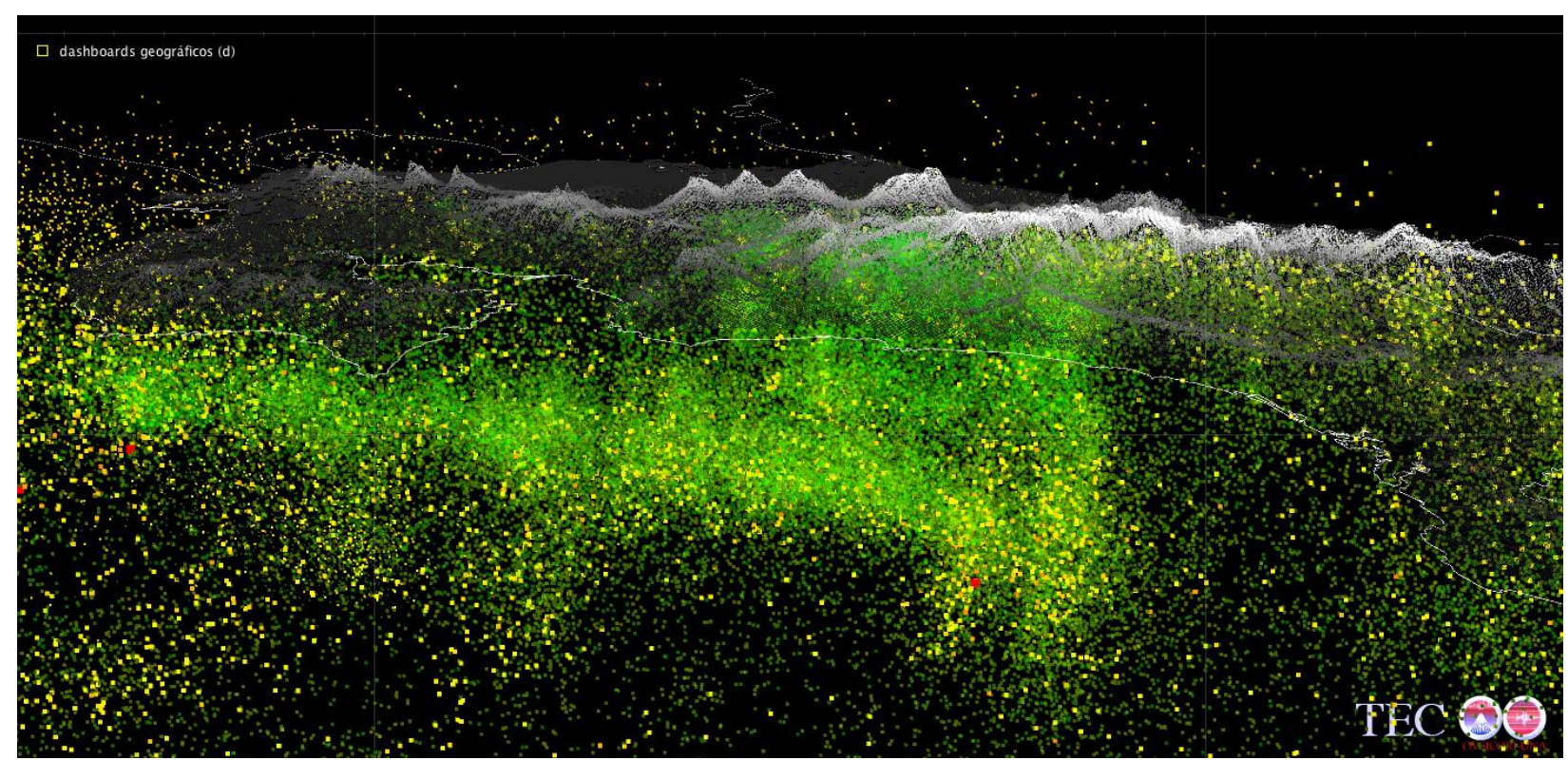

Fig. 8. Example of earthquake visualization where point color (green, yellow, red) and size are used to represent earthquake magnitude 
It is worth noting that $3 \mathrm{D}$-perspective views always imply a focus-plus-context effect because in natural human view the perspective makes faraway objects smaller and closer objects bigger for the observer. This process is one of the advantages of having a $3^{\mathrm{D}}$ view of more than 100000 hypocenters: the seismologist can turn around, get closer, or move further away in order to catch precisely the object of interest.

\subsubsection{Defining seismic profiles}

Perhaps the most important and time-consuming task performed by seismologists is defining seismic profiles. The objective is to determine vertical cross-section cuts and thereby analyze tectonic plate subduction trends. As reflected in figure 4, this step is viewed in 2D.

Questions like, "what is the behavior of the tectonic plate and its geometric direction?" and "how is the geometry of subduction area?" are the kind of topics that the scientists answer with these profiles.

With Plinius, when the user indicates that he/she wants to define a new profile, the tool moves the point of view to a unique orthogonal place to facilitate the conventional method that scientists use to introduce three points. The first two points define a line, and the third establishes the width of the profile. In this way, a procedure that previously took days now can be carried out in seconds (figure 9).

This feature of Plinius enables the scientist to make several profiles in minutes, which is important because of data occlusion. Usually, if you look at a cross-section of the hypocenter data, you will see all the points behind the zone of interest. With Plinius, you can, in seconds, cut out all these points of the perspective and concentrate in the desired profile (typically used to see seismic subduction plates), testing over and again if you do not get the result that you want. More details of work with seismic profiles in Plinius are described in [28]

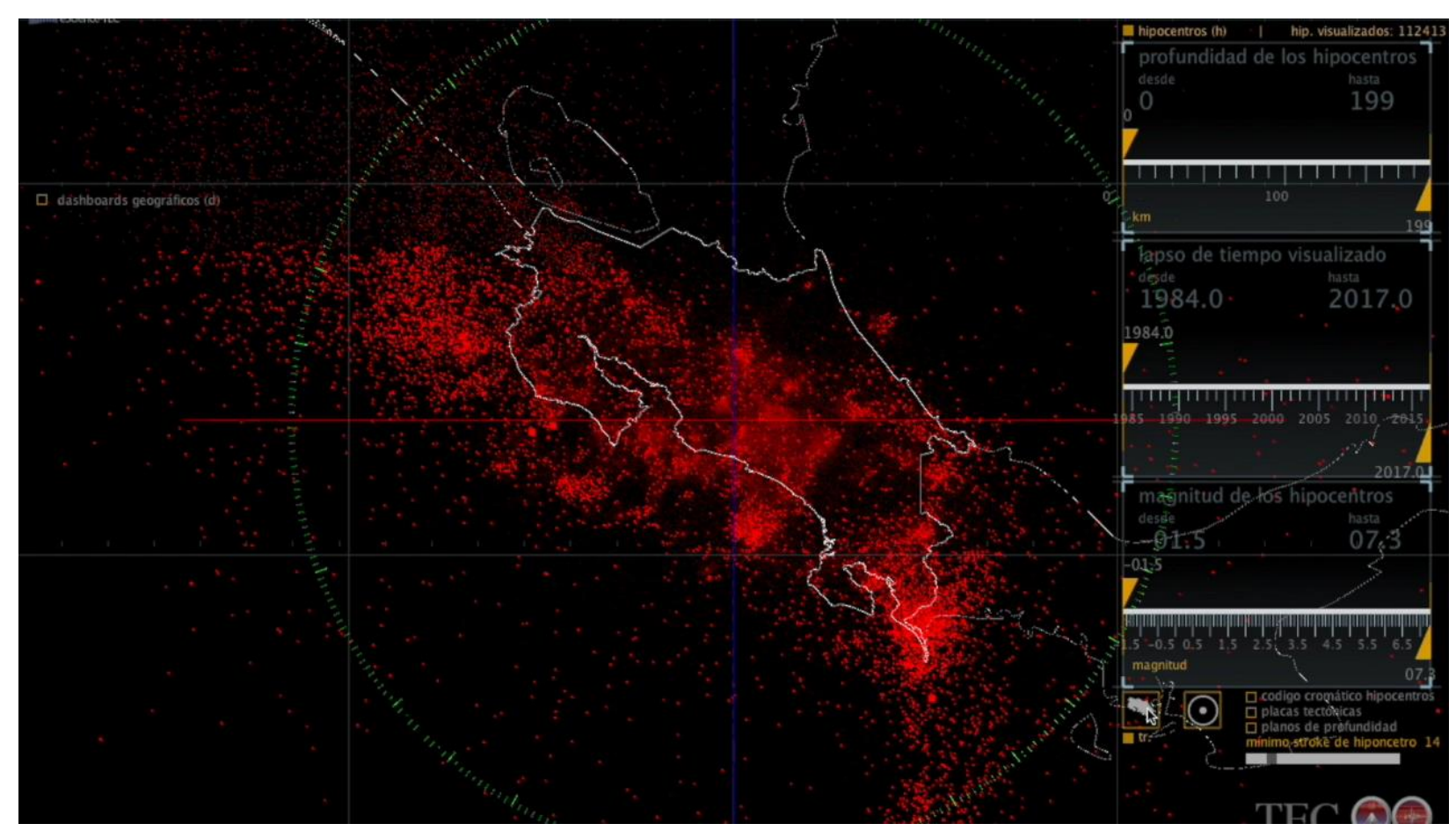

Fig. 9. Defining seismic profiles by Plinius

\subsubsection{Plate geometry}

With this data, scientists can define the shape of the tectonic plates and the geometry in which one is subduced into the other. To observe this geometry in three dimensions, Plinius can visualize this geometry and in turn mix it with all other data and filters, giving users the ability to see this geometry in context (see figure 10). 


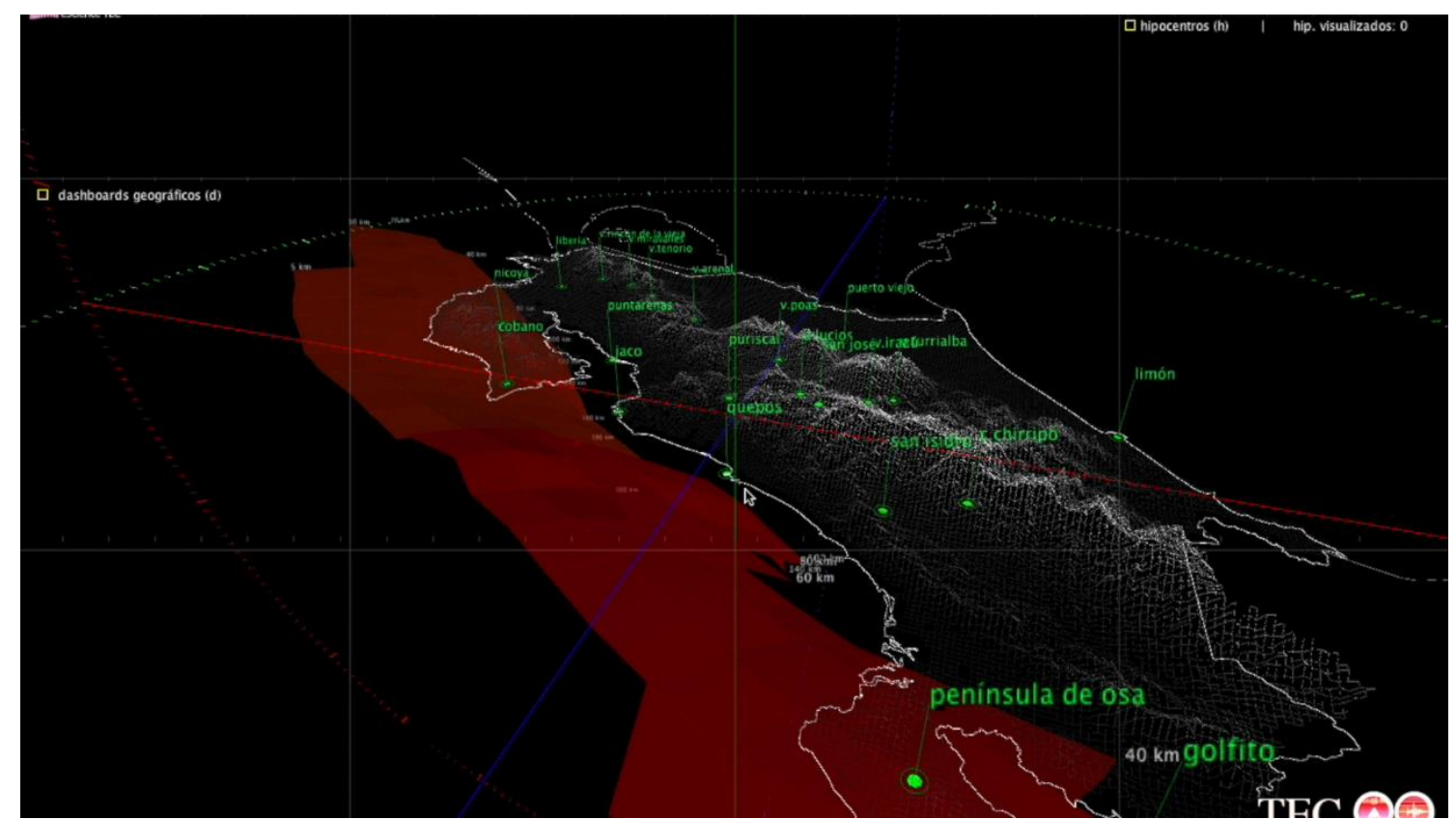

Fig. 10. Geometry of the subduction zone

\subsubsection{Determining Cylindrical Areas}

The objective of this filter is to determine cylindrical cross-section cuts and thereby analyze local failures and volcanic behaviors. This feature was asked for by the scientists when they were able to see, for the first time, only surface earthquakes, they decided that it would be useful to be able to isolate specific areas. These areas with points of interest on the surface (e.g., volcanoes, local faults, cities, and coastal locations), would be separated and could be analyzed quickly with close-ups and rotations of the associated swarm of earthquakes (as shown in figure 6 above).

To do that, we use two points: the first is the central position of the cylinder (usually a volcano, a local fault, or a city of interest); the second is the ratio of the desired area, the width of the cylinder (see figure 11). In this way, seismologists can isolate a local area with all hypocenters underneath it, then potentially filter for magnitudes, periods, or depths with the other sliders, as shown in figure 11 (Irazú Volcano in Costa Rica).

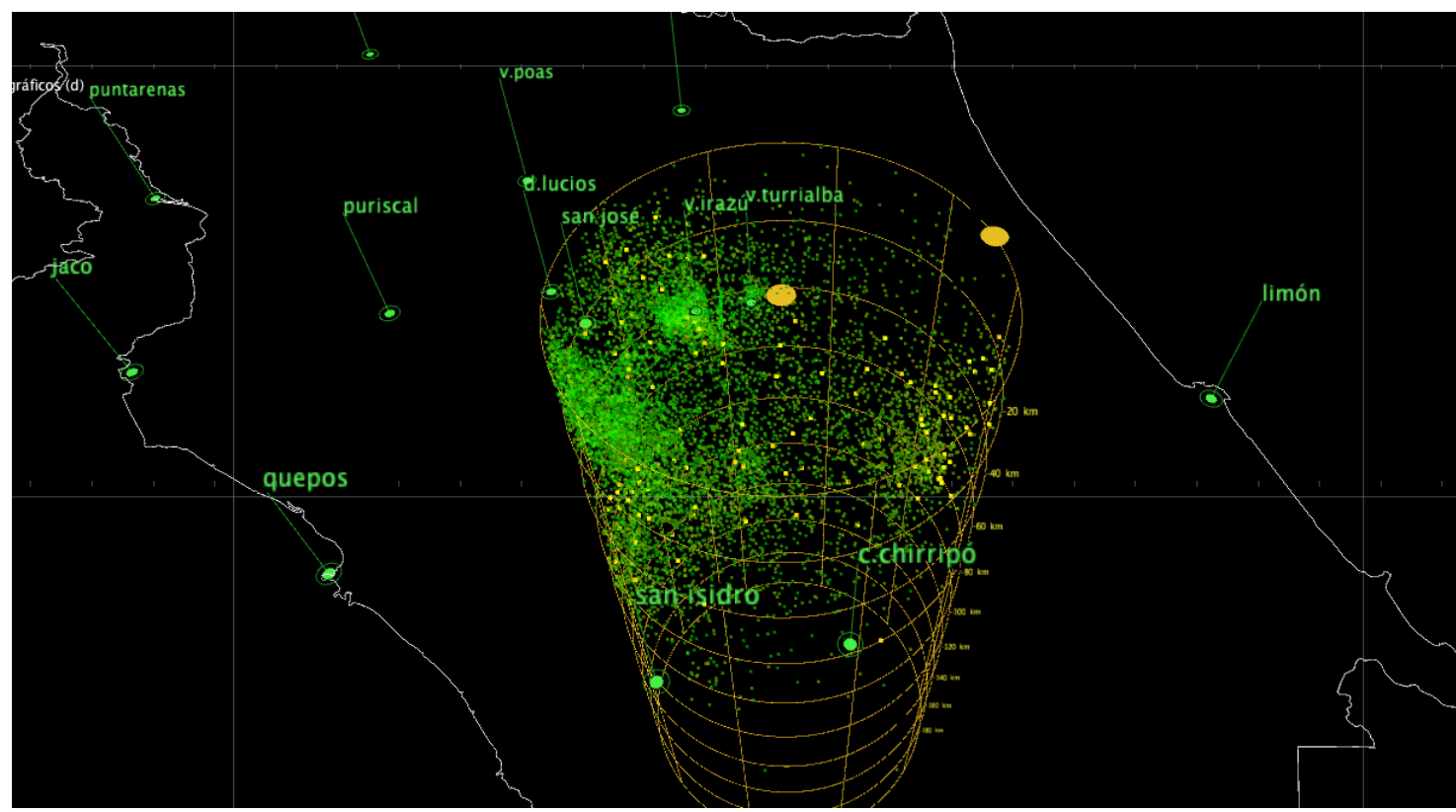

Fig. 11. Cylindrical area of interest defined by seismologists, allowing visualization of the Irazú volcano zone in Costa Rica 


\subsection{Plinius technical background}

The entire Plinius system was developed using Processing 3.o (https://processing.org), which is a free software platform developed by the Massachusetts Institute of Technology and is functional on Windows, macOS, and Linux operating systems. In other words, from Processing it is possible to export a tool that works in any of these operating systems.

The Processing platform is a Java dialect and uses as a $3 \mathrm{D}$ engine a version of OpenGL, specifically OpenGLES. This configuration allows it to represent moderately complex threedimensional models with good features, in our case the efficiency is good up to a maximum of one million points.

This system was tested in its efficiency with two other development environments, Three.js (https://threejs.org/), and apple-swift language with OpenGL-ES (tested in early 2017 at the beginning of the project). In all tests performed Processing resulted in much higher efficiency [29].

Part of the idea of this project was to offer scientists a tool with which they could analyze in three dimensions the data available in their office, without needing a computer cluster or a high-efficiency computer. Thus the tool was optimized to run on a medium-capacity personal computer. In the final stages of the project, several tests were successfully carried out to verify that the system could run on the scientists' computers.

In the case of Plinius, the geography of Costa Rica was loaded through a CSV file, which in turn was garnered from a GeoTiff type image, obtained from the database of the PRIAS project of the National Center for High Technology of Costa Rica (CeNAT http://www.cenat.ac.cr/en/prias-en/).

On the other hand, the hypocenter positions were obtained from OVSICORI (http://www.ovsicori.una.ac.cr) and fed to the system through a file of 140 ooo rows, also of the CSV type. The data contained for each row an event with its longitude, latitude, depth, magnitude, day, month, year, etc.

The only extra library used for the system was the "processing.pdf" because the system is able to save files of what was displayed in PDF format, all the rest of the features, including interactive elements such as sliders and buttons were programmed from scratch in Processing.

For navigation in three-dimensional space, we used the system that our research group iReal had already generated and tested in other projects, which is a version adapted to the geography of the traditional navigation scheme "virtual sphere" [26].

To avoid occlusion problems the only rendering technique used in visualization is wireframe, so geography, plate tectonic planes or other objects do not hinder the observation of the hypocenters behind them. This rendering technique also helps to improve efficiency as it is a technique that requires low use of computational capabilities.

\section{Usability Evaluation}

Through the design and development process of Plinius, we conducted several tests with a group of $5-7$ scientists from the Volcanological and Seismological Observatory of Costa Rica (OVSICORI: http://www.OVSICORI.una.ac.cr).

Some user interactions (such as the three points to define a seismic profile) are the conventional way to set these configurations in the domain disciplines. Because of this, when users want to identify one of these areas, Plinius takes an orthogonal position to allow the usual data entry, since users are accustomed to working in two dimensions. Other interactions, like the cylindrical filter, are entirely new in the domain practices.

The obvious step forward for scientists using Plinius is the possibility to see, for the very first time, a $3 \mathrm{D}$ visualization of earthquake swarms with the options of zooming in and out and rotating in all directions. Previously, they could only decide a profile or area of interest, filter the data from the database, and visualize a section of this selected data. This process took several hours, and in the end, they only saw a 2D cut - if it was not what they were looking for, they would have to start the process all over again. 
We conducted a post-use qualitative evaluation survey to compare the experience of Plinius to the traditional approach. Seismologists were asked which approach they found more intuitive, what they would prefer to use in the future, and which of the two methods they think is easier to use. Most users and observers said that this tool is much more intuitive and, above all, much faster than all the tools they use currently.

In all cases, we found that the visualization was correctly used by the scientist, with minimal training required.

\section{Conclusions and Future Work}

The aforementioned validated cases prove that Plinius is a useful tool for scientists. Hypocenter data is naturally found in three dimensions, yet traditionally, scientists have only been able to visualize such data using $2 \mathrm{D}$ cuts.

Plinius now allows data to be seen as it truly is, to scale, and how it naturally relates to other data such as geography, positions of cities, volcanoes, and other important sites. Through Plinius, the subduction of the Cocos Plate under the Caribbean Plate, as well as the Panama Block can now be visualized in three dimensions (figure 12).

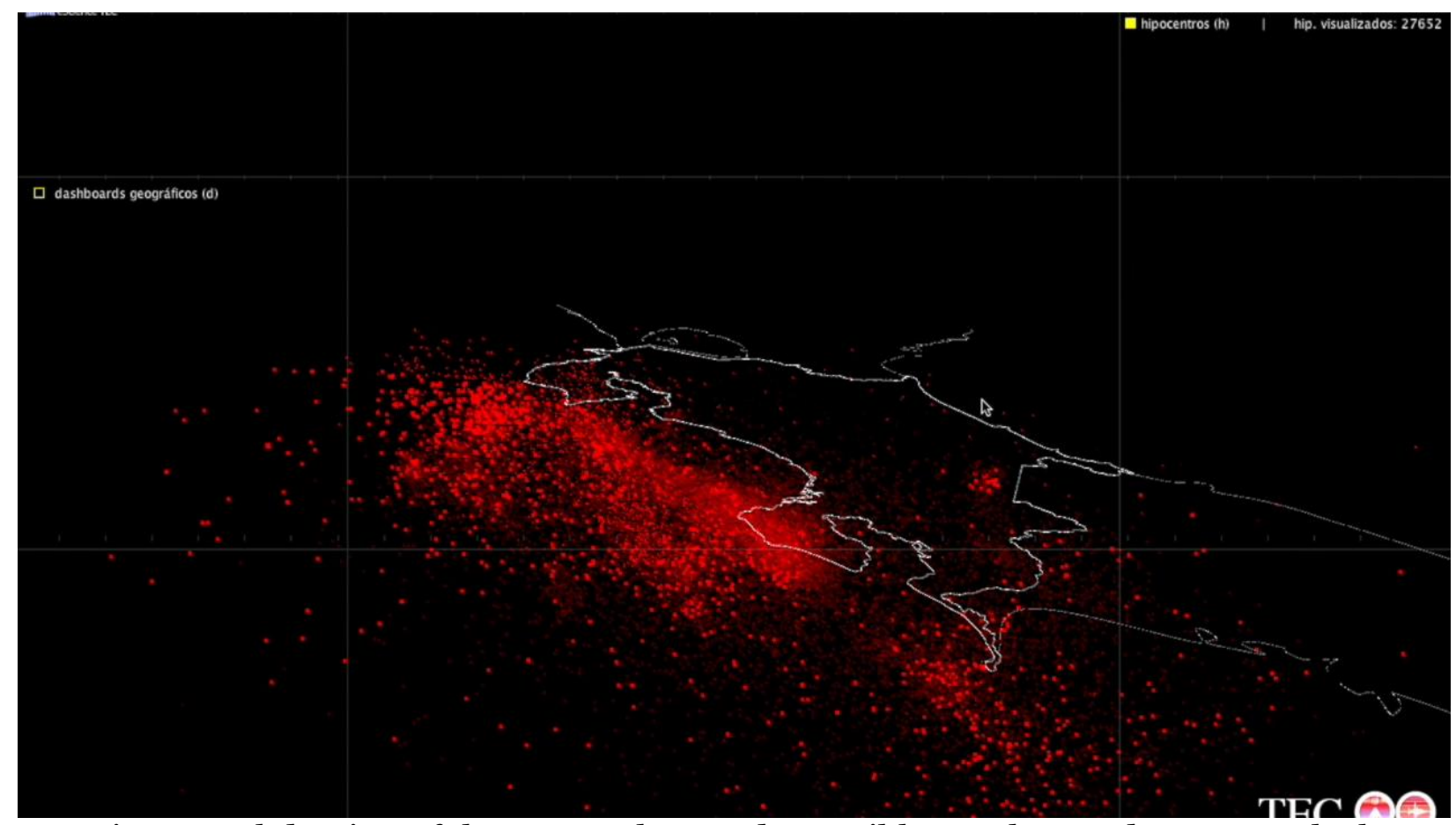

Fig. 12. Subduction of the Cocos Plate under Caribbean Plate and Panama Block

Future prospects include adding ongoing seismology research results to Plinius. One example is to incorporate lines to reflect plate geometry, which would allow users to visualize the true geometry of the tectonic plates.

While our tool responds satisfactorily to the requirements defined by seismologists, an interesting suggestion is given by $\mathrm{Ma}$ et al. [30]: adding to the tool a new dashboard that would allow users to have statistical information such as scatter plots, box plots, and histograms. This dashboard would be a complement to the visual part and would strengthen the exploratory data analysis inside the system.

This approach is consistent with the work developed in VisTravel [1], a system that includes eight views, several of which depict statistical information. The primary objective of these systems is to allow users a multi-perspective analysis.

The whole system was developed in a standardized way from the data with its longitudes, latitudes, and depth, with the idea of making it easy to adapt to other cases. In other words, the 
tool can visualize a set of hypocenters anywhere in the world and continue to use filters, navigations and other features immediately.

On the other hand, the whole project was developed in a Public University in Costa Rica entirely with public funds, and therefore it is open to collaborating in the adaptation of this tool or its components with any other group of researchers that so wishes or needs it.

\section{Acknowledgment}

We wish to thank the Volcanological and Seismological Observatory of Costa Rica at National University, OVSICORI (http://www.OVSICORI.una.ac.cr). We would also like to thank the scientists who provided assistance as consultants, testers, and advisers.

Finally, we give thanks to the eScience research program to which our iReal group belongs, which has supported this project in all aspects of its administration and funding.

\section{References}

[1] Q. Li, Y. Wu, S. Wang, M. Lin, X. Feng andH. Wang. VisTravel: visualizing tourism network opinion from the user generated content. Journal of Visualization, 19(3), 489-502, 2016.

[2] F. Hernandez-Castro, J. Monge-Fallas, M. Méndez-Morales, M. Protti-Quesada Animation: Crustal Deformation in the Nicoya Peninsula Associated with the September 5th, 2012 Earthquake. Scientific Visualization. 2018;10(3): 29 - 47, DOI: 10.26583/sv.10.3.01.

[3] C. Kyriakopoulos, A. V. Newman, A. M. Thomas, M. Moore-Driskell and G.T. Farmer, G. T. A new seismically constrained subduction interface model for Central America. Journal of Geophysical Research: Solid Earth, 120(8), 5535-5548, 2015.

[4] J. Meyer and T. Wischgoll. Earthquake visualization using large-scale ground motion and structural response simulations. In Scientific Visualization: The Visual Extraction of Knowledge from Data (pp. 409-432). Springer, Berlin, Heidelberg, 2006.

[5] W. Dzwinel, D. A. Yuen, K. Boryczko, Y. Ben-Zion, S. Yoshioka and T. Ito. Cluster analysis, data-mining, multi-dimensional visualization of earthquakes over space, time and feature space. Nonlinear Processes in Geophysics, 12, 117-128, 2005

[6] K. M. Fairchild, S. E. Poltrock and G. W. Furnas. Semnet: Three-dimensional graphic representations of large knowledge bases. In Readings in information visualization (pp. 190206). Morgan Kaufmann Publishers Inc, January 1999.

[7] S. E. Palmer. Modern theories of Gestalt perception. Mind \& Language, 5(4), 289-323, 1990.

[8] X. Tao. Research on information visualization design based on cognitive theory. In Design Management Symposium (TIDMS), 2013 IEEE Tsinghua International (pp. 123-126). IEEE, December 2013.

[9] A. Figueiras. Towards the understanding of interaction in information visualization. In Information Visualisation (iV), 2015 19th International Conference on (pp. 140-147). IEEE, July 2015.

[10] R. Fernandez and N. Fetais. Survey of Information Visualization Techniques for Enhancing Visual Analysis. In Computer and Applications (ICCA), 2017 International Conference on (pp. 360-363). IEEE, September 2017.

[11] N. Prapaitrakul and S. Phithakkitnukoon. EQviz: a visualization tool for monitoring world earthquakes. In Adjunct Proceedings of the 2015 ACM International Joint Conference on Pervasive and Ubiquitous Computing and Proceedings of the 2015 ACM International Symposium on Wearable Computers (pp. 1207-1211). ACM, September 2015.

[12] C. Willmesa, J. Weskamma, U. Baaser, K. G. Hinzen and G. Bareth. SeismoGIS: A tool for the visualization of earthquake data. In Proc. XXI ISPRS congress (Beijing, China, 3-11 July (Vol. 2008, p. 1239), 2008.

[13] R. H. Wolfe and C. N Liu. Interactive visualization of $3 \mathrm{D}$ seismic data: A volumetric method. IEEE Computer Graphics and Applications, 8(4), 24-30, 1988. 
[14] D. Patel, C. Giertsen, J. Thurmond, J. Gjelberg and E. Grøller. The seismic analyzer: Interpreting and illustrating $2 \mathrm{~d}$ seismic data. IEEE transactions on visualization and computer graphics, 14(6), 1571-1578, 2008.

[15] G. Leonard, Z. Somer, Y. Bartal, B. Y. Horin, M. Villagran and M. Joswig. GIS as a Tool for seismological Data Processing. In Monitoring the Comprehensive Nuclear-Test-Ban Treaty: Data Processing and Infrasound (pp. 945-967). Birkhäuser, Basel, 2002.

[16] A. Chourasia, S. Cutchin and B. Aagaard. Visualizing the ground motions of the 1906 San Francisco earthquake. Computers \& Geosciences, 34(12), 1798-1805, 2008.

[17] R. H. Wolfe and C. N Liu. Interactive visualization of 3D seismic data: A volumetric method. IEEE Computer Graphics and Applications, 8(4), 24-30, 1988.

[18] B. T. Aagaard,T. M. Brocher, D. Dolenc, D. Dreger, R. W. Graves, R, S. Harmsen and M. L. Zoback.. Ground-motion modeling of the 1906 San Francisco earthquake, Part I: Validation using the 1989 Loma Prieta earthquake. Bulletin of the Seismological Society of America, 98(2), 989-1011, 2008.

[19] D. Patel, C. Giertsen, J. Thurmond, J. Gjelberg and E. Grøller. The seismic analyzer: Interpreting and illustrating $2 \mathrm{~d}$ seismic data. IEEE transactions on visualization and computer graphics, 14(6), 1571-1578., 2008.

[20] L. Castanie, F. Bosquet and B. Levy. Advances in seismic interpretation using new volume visualization techniques. first break, 23(10), 2005.

[21] M. Ivančić, Ž. Mihajlović and I. Ivančić. Seismic data visualisation. In Information and Communication Technology, Electronics and Microelectronics (MIPRO), 2015 38th International Convention on (pp. 324-327). IEEE, May 2015.

[22] X. Liu, D. Li, Y. Xu and W. Xu. Research on 3D Visualization Method of Seismic Data. International Journal of Signal Processing, Image Processing and Pattern Recognition, 9(5), 441-454, 2016.

[23] D. A. Yuen, B. J. Kadlec, E. F.Bollig, W.Dzwinel, Z. A. Garbow and C. R. da Silva. Clustering and visualization of earthquake data in a grid environment. Visual Geosciences, 10(1), 112, 2005.

[24] J. W. Stoecker. TerraVis: A Stereoscopic Viewer for Interactive Seismic Data Visualization, 2011.

[25] T. J. Hsieh. Understanding earthquakes with advanced visualization. ACM SIGGRAPH Computer Graphics, 44(1), 4, 2010.

[26] F. Hernandez-Castro \& J. Monge-Fallas. Navigation Sphere: Optimizing Virtual Sphere for Terrains Analyses. PONTE: International Scientific Researches Journal, 74(7), 2018.

[27] B. Saket, A. Srinivasan, E. D. Ragan and A. Endert. Evaluating interactive graphical encodings for data visualization. IEEE transactions on visualization and computer graphics, 2017

[28] J. Monge-Fallas \& F. Hernández-Castro. An Intuitive 3D Interface for Defining Seismic Profiles by Plinius. PONTE: International Scientific Researches Journal, 74(4), 2018. doi: 10.21506/j.ponte.2018.4.9

[29 ] F. Hernandez-Castro, J. Monge-Fallas. Eficiencia comparativa en animaciones en javascript. Tecnología en Marcha. 31(3), 142-149, Julio-Setiembre 2018.

[30] X. Ma, D. Hummer, J. J. Golden,P. A. Fox R. M. Hazen, S. M. Morrison and M. B. Meyer. Using Visual Exploratory Data Analysis to Facilitate Collaboration and Hypothesis Generation in Cross-Disciplinary Research. ISPRS International Journal of Geo-Information, 6(11), 368, 2017. 